\title{
CONFIGURAÇÕES TERRITORIAIS EM TRÊS ROMANCES CONTEMPORÂNEOS À LUZ DOS CONCEITOS DE PÓS- AUTONOMIA LITERÁRIA DE JOSEFINA LUDMER
}

\author{
Christine Kath \\ Universidade de Lisboa \\ tine.kath@gmail.com
}

Resumen: En el presente artículo se desarrolla una reflexión acerca de las recientes transformaciones de los espacios urbanos representados en la literatura rioplatense contemporánea. Se estudian las expresiones de territorialidad a partir de las propuestas articuladas por Josefina Ludmer en Aqui América Latina: Una especulación, de 2010. El concepto de "postautonomía" es allí introducido junto con otros relacionados, de los cuales se examina el de "isla urbana". Se analizan tres novelas urbanas de Aira, Piglia y Levrero, con fechas de publicación en los años 80, 90 y 2000, cuyo objetivo es estudiar las propuestas de Ludmer y establecer asimismo una relación con la "heterotopía" de Michel Foucault.

Palabras clave: Espacio urbano, Postautonomía, Heterotopía, Isla urbana.

\begin{abstract}
This article reflects on the recent transformations of the urban spaces represented in the contemporary literature of the Río de la Plata region. It studies the expressions of territoriality based on the proposals of Josefina Ludmer made in Aqui America Latina: Una especulación, de 2010. In it, Ludmer introduces the concept of post-autonomy along with several related concepts, of which "urban island" is examined in this article. Three urban novels by Aira, Piglia and Levrero, published in the 80 's, 90's and 2000's, are analyzed to study Ludmer's proposals and a relationship with the "heterotopia" of Michel Foucault is established.
\end{abstract}

Keywords: Urban space, Postautonomy, Heterotopia, Urban island. 



\section{A crise da autonomia literária segundo Ludmer}

Para Josefina Ludmer (1939-2016) estamos, na viragem do milénio, a entrar numa era que constitui, em termos literários e culturais, uma evidente rutura com o tempo anterior. Tendo o intuito de compreender o mundo da literatura, afetado pelas recentes transformações globais e os fortes impactos locais com elas relacionados, Ludmer introduz o conceito de "pósautonomia". Apresentado e divulgado pela autora em diversos artigos, conferências e entrevistas, o tema é desenvolvido no ensaio Aqui América Latina: Una especulación, publicado em 2010. Com o termo "pós-autonomia", a ensaísta designa a etapa atual como uma progressiva dissolução, ou tendência de encerramento, da época de "autonomia" da literatura, que tinha sido aberta pela modernidade, acarretando uma transformação crucial da relação entre realidade e literatura. Ludmer leva a cabo um estudo de vários textos narrativos latino-americanos contemporâneos que evidenciam esta transformação. Segundo a autora, o processo de perda de autonomia, e as mudanças de produção e receção literárias diretamente relacionadas, são "nitidamente" visíveis em algumas escritas do presente. São ficções que "atravessaram a fronteira literária" em êxodo ou diáspora, e é para estas que a autora cunhou o termo "pós-autónomas" (Ludmer, 2010, p. 153). Na obra, dividida em dois eixos principais: Territorios e Temporalidades, Ludmer cria e utiliza as seguintes ferramentas teóricas como conceitos-chave: "imaginação pública" (ou

\footnotetext{
${ }^{1}$ A tradução deste termo e dos outros termos-chave de Ludmer é da autora.
} 
"fábrica de realidade"), "autonomia" e "pós-autonomia", "tempo zero", "cronopolítica", "exposição universal" e "ilha urbana". Considerando os conceitos de autonomia e do valor literário o coração do seu conjunto de propostas, chama a atenção que Ludmer determine o que entende como autonomia sobretudo pela negativa, dizendo que as literaturas autónomas são aquelas que já quase não se escrevem, e aquelas que tradicionalmente obedeciam às regras do campo sociocultural da literatura, descrito por Pierre Bourdieu.

Embora a sua posição foi e é intensamente debatida no âmbito dos estudos literários, não me vou a dedicar neste lugar à receção ${ }^{2}$ de Aquí América Latina ou à discussão da obra em geral, mas sim restringir o foco a um aspeto central dela: no que concerne à representação do espaço urbano nos romances contemporâneos. Da sua obra, que se ramifica e abrange muitos temas, considero a noção de "illhas urbanas" especialmente interessante porque entre os termos propostos este é um que a ensaísta mais desenvolve.

\footnotetext{
2 Aquí América Latina foi criticada pelo vago uso da noção de autonomia, sobretodo respeito ao longo e diferenciado uso deste termo na história literária (Dalmaroni, 2010). A publicação foi elogiada pela sua audácia teórica já que deixa atrás categorias clássicas e dá fé a uma nova posição diaspórica da literatura com novas práticas e formas (Giordano, 2010, pp. 9-10). Dalmaroni e Topuzian apontaram para uma inconsistência entre teorizações e corpus, sendo que Ludmer pretende, ao avaliar o sistema literário pós-autónomo, suprimir todos os juizios de valor literario, porém inclui nas suas leituras apenas obras com obvia autorização cultural (Dalmaroni, 2010 cit. em Topuzian, 2013, p. 321).
} 


\section{Territórios urbanos e "ilhas urbanas"}

À luz desta parte das teorizações de Ludmer, empreendo neste exercício uma análise comparativa dos espaços representados em três romances: em París (1980) do uruguaio Mario Levrero ${ }^{3}$, La ciudad ausente (1992) do argentino Ricardo Piglia e La villa (2001) do também argentino César Aira. Seguindo as datas de escrita, os romances representam, nas propostas de Ludmer, a época imediatamente anterior e a época de entrada da pós-autonomia literária. Ainda assim, admitem-se diferentes maneiras de os ler, pois segundo estabelece Ludmer, a ambivalência veio a ser o novo regime (político e económico) das ficções do presente:

Aparecen como literatura pero no se las puede leer con criterios o categorías literarias como autor, obra, estilo, escritura, texto y sentido. No se las puede leer como literatura porque aplican a la literatura una drástica operación de vaciamiento: el sentido (o el autor, o la escritura) queda sin densidad, sin paradoja, sin indecidibilidad [...], y es ocupado totalmente por la ambivalencia: son y no son literatura, son ficción y realidad. (Ludmer, 2010, p. 150)

Ludmer oferece o juízo ao leitor: "O se ve el cambio en el estatuto de la literatura en el interior de la industria de la lengua, y entonces aparecen otros modos de leer. $\mathrm{O}$ no se lo ve

\footnotetext{
3 Escrito em 1970, primeiramente publicado em 1979/1980, París integra juntamente com La ciudad (escrito em 1966, publicado 1970) e El lugar (escrito em 1969, publicado em 1982) a trilogia que Levrero posteriormente chamou Trilogía involuntaria. Optou-se por utilizar as datas referidas na edição Debolsillo que inclui os três romances da trilogia e vários prólogos. Para evitar confusões, coloca-se entre parênteses o ano da publicação original para assim distinguir de que parte da trilogia se está a referir.
} 
o se lo niega (no se imagina que estamos en otro mundo) [...]" (Ludmer, 2010, p. 155). Ludmer esclarece em repetidas ocasiões que entende a sua análise como um convite a pensar, um rascunho, uma imaginação de casos hipotéticos considerando-se a especulação e a agitação os modos de enunciação do seu ensaio. A localização dos três romances num lado ou noutro da transição entre autonomia e pósautonomia não constitui, em si, o objetivo deste trabalho. Se assim fosse, e, presumindo que se tratara duma transformação possível de fixar numa data, bastaria ver o ano de publicação de cada obra. No entanto, é feita uma tal localização dos romances associados a "el borde del sistema autónomo" (Ludmer, 2010, p. 93) na tentativa de esclarecer a noção de "pós-autonomia" de Ludmer.

Sandra Contreras explica que, segundo Ludmer, as ficções pós-autónomas são politicamente ambivalentes porque querem pertencer a várias categorias ao mesmo tempo, e na sua dimensão económica porque não se sabe se certos valores que possuem são positivos ou negativos. A ambivalência é tanto característica dos objetos que se lêem, como condição da leitura do presente, e isto torna impossível, ou impertinente, atribuir-lhes um valor literário (Contreras, 2010, p. 146).

Sintetizando o argumento dos três romances, pode dizer-se que os três contam histórias de pesquisas em espaços urbanos: o percurso errante de Maxi pelo bairro bonaerense de Flores, como forma de passar o tempo, de ajudar os vizinhos e, de compreender a enigmática situação dos moradores da villa; a viagem de Junior por Buenos Aires e pelo interior do país para investigar a máquina de narrar num tempo de tensão política; e 
a viagem do narrador nos romances de Levrero em busca de si mesmo e da saída da cidade labiríntica, determinada pelo desejo, sempre frustrado, de pertencer socialmente, unir-se com um lugar ou uma companheira. Os três romances têm como temas comuns: a vigilância estatal, a violência policial, e ainda o jornalismo. Salienta-se um clima de angústia ou de falta de esperança, que pode ser interpretado como anúncio ou alusão ao "fim do mundo", ou ainda ao "fim do sentido" que refere Ludmer. Argumentando que os seus protagonistas são as próprias cidades com ênfase na sua função vital, a circulação das mercadorias materiais e simbólicas que nelas ocorre, $O$ tema-base das três narrativas de diferentes contextos torna-se coincidente.

Em relação ao espaço, as suas caracterizações básicas podem resumir-se assim: o romance de Piglia reflete sobre o espaço político e literário argentino em contexto com discursos de memória e identidade, na cidade capital. Em La villa, César Aira trabalha sobre o espaço limiar entre territórios de diferentes grupos sociais, através da criação de personagens que circulam por cima de certas fronteiras criadas no centro da cidade. Nos romances de Mario Levrero desenvolvem-se ideias sobre o espaço pessoal enquanto inserido no espaço público. Através de observações sobre a vida mental e anímica da personagem principal, narra-se em primeira pessoa sobre o lugar do "eu" na cidade, podendo ser entendido como um relato da crise entre o sujeito e o seu entorno moderno. La ciudad, primeiro romance na Trilogía involuntaria, finaliza com a saída do protagonista-narrador da cidade anónima quando consegue comprar um bilhete de comboio para retornar a 
Montevideu (Levrero, 2016 [1970], p. 155). No segundo romance, El lugar, o protagonista encontra-se numa espécie de labirinto urbano duma cidade indefinida, cheia de corredores e habitações em ruínas, mas no final consegue ir até o campo e seguir para outra cidade, também ela sem nome, e que talvez seja aquela de que partiu. Em París, a personagem principal e narrador carece de nome e particularidades, move-se pela cidade confusa e consegue voar e vê-la do céu.

O romance de César Aira é usado pela ensaísta para explicar a sua tese. Nele encontra-se a configuração temática ou estilística que Ludmer chama de "ilha urbana", os espaços que representa, poderiam estar situados em qualquer parte de América Latina (Ludmer, 2010, p. 149) e não permite uma leitura literária tradicional. Dos três romances escolhidos, este seria o que se entende mais diretamente como pós-autónomo. A inclusão de romances de Ricardo Piglia e do uruguaio Mario Levrero no corpus introduzem um forte contraste a diferentes níveis. Ao invés dos romances de Aira e Levrero, a obra de Piglia trabalha com a memória nacional. Ludmer chama "escritores-intelectuales" os escritores em contraposição com os autores das ficções do tipo pós-autónomo (Ludmer, 2010, p. 89). Parte-se do pressuposto que o romance La ciudad ausente seria exemplo classificável como literatura autónoma. Não obstante, abre-se a discussão sobre este romance para pôr em questão esta suspeita inicial para experimentar e ver se, contrariando a previsão, julgando pelo modo de representação dos espaços, La ciudad ausente poderia eventualmente também ser lido como literatura pós-autónoma. Para o romance do autor uruguaio Mario Levrero, que parece não se assemelhar 
nem ao modelo do escritor-intelectual nem ao do mediático, não há, pelo menos à primeira vista, indícios que permitam formular uma hipótese clara para o associar à literatura autónoma ou pós-autónoma excetuando o facto de ter sido publicado muito antes da data de rutura definida por Ludmer.

\section{Noções territoriais de Ludmer}

$\mathrm{Na}$ palestra dada no âmbito da Cátedra Alfonso Reyes, Monterrey, em 2007, Ludmer expôs como a conjuntura de processos políticos, económicos, sociais e estéticos de origens diversas, formada por volta dos anos 1990, interfere com os espaços urbanos e a literatura a eles vinculada. Ludmer assumiu que os espaços da América Latina são profundamente alterados nesse cruzamento de acontecimentos e influências, a que refere como sendo a nova configuração do capitalismo global. A partir daí, originou-se a necessidade de renovação do pensamento em relação às classificações dos géneros $\mathrm{e}$ fronteiras literários e de renovação da organização de abordagens e metodologias. Para o efeito, concluiu, as noções espaciais podem ser de grande utilidade. No seu discurso desenvolveu esta ideia em três figuras teóricas: a "exposição universal", a "cidade" e a "ilha urbana", as mesmas que logo foram aprofundados em Aqui América Latina. De acordo com Ludmer, é relevante para a crítica literária contemporânea estudar a cidade latino-americana porque se passou a considerá-la como imagem da sociedade, substituindo a fábrica que antes prevalecia no imaginário público. Ludmer assinala 
que percorrendo a cidade é possível "ler" os diferentes sectores e até os pormenores mais refinados da sociedade, também a nação e o global se encontram nela representados, e que é por isso uma das bases em que se apoia ao formular a sua teoria sobre uma entrada na época da pós-autonomia (Ludmer, 2014).

O final do século XX, que coincide com o final do ciclo da autonomia literária na América Latina, é o momento em que a oposição campo-cidade é posta em questão, processo ao que Ludmer refere como o trabalho de reorganização de fronteiras. Enquanto a literatura rural ainda podia ler-se através dos autores do boom de literatura latino-americana, nos relatos que, como argumenta a autora, se tornaram os lugares da identidade nacional, depois dos anos 70 já não se pensa a América Latina como rural, campesina, prevalecendo na atualidade uma literatura especificamente urbana, carregada de sexo, droga, miséria e violência. A cidade absorve e inclui o campo com os seus mitos, dramas e personagens. A cidade barbariza-se, torna-se uma selva. Ludmer conclui que a favela ou villa miseria vem a ser o espaço emblemático da relação da América Latina com a globalização (Ludmer, 2010, p. 124).

Néstor García Canclini, que realizou uma síntese da história do pensamento moderno sobre a cidade, explica que um dos traços característicos das cidades nos finais do século XX é que passaram de ser centralizadas a ser policêntricas, multifocais. Devido ao seu grande tamanho e à sua heterogeneidade, perdeu-se a noção do conjunto. Agora há, por exemplo, helicópteros que diariamente sobrevoam o ar sobre a "megalópolis", observam o trânsito e transmitem na televisão 
para mostrar como está a cidade desde cima, "quase como Deus". Segundo o autor trata-se dum simulacro bastante eficaz, que ajuda as pessoas a orientarem-se e assim desenvolvem imaginários sobre aspetos da cidade que nunca podem e talvez nem queiram conhecer com os próprios olhos. Estes novos atores sociais, produto da industrialização das comunicações, parecem ter substituído os tradicionais (García Canclini, 2010, p. 85). Em Aqui América Latina Ludmer assinala a constatação de Jean Franco: "[Franco] [d]ice que las ciudades-megalópolis no pueden ser imaginadas como totalidad, comunidad, identidad y subjetividad: tienen que ser pensadas desde fragmentos y ruinas" (Ludmer, 2010, pp. 142143). A descrição de Buenos Aires feita em La villa de Aira coincide com as imagens que traçam García Canclini e Ludmer na medida em que perante a perda do conjunto, a câmara municipal usa aviões e helicópteros, mostrando a dificuldade de controlar a transformação da cidade. Os personagens Maxi e a menina da "villa" conversam sobre isso: " $-\dot{ }$ Viste que hay gente que siempre le está haciendo refacciones a su casa, y nunca se dan por satisfechos? Así es Dios. Entre los seres humanos está tan difundida esa manía, que la municipalidad ha tenido que poner aviones para sacar fotos aéreas. Así pueden ver qué reformas ha hecho, y ajustan los impuestos" (Aira, 2001, p. 106).

Em La ciudad ausente de Piglia também se perdeu a visão do conjunto da cidade, mas de uma maneira diferente, já que o espaço narrado não se restringe a um bairro, pois o protagonista encontra-se muitas vezes a caminho, no trânsito ou de viagem. Isto também é válido para París de Levrero onde 
o desejo de voar pode ser o desejo de ver a cidade no conjunto. A experiência do protagonista é inquietante devido à falta de claras marcas de referência espaciais, tal como ocorre com as aventuras da mesma personagem em La ciudad e El lugar (Rivadeneira, 2014, p. 109).

No seu ensaio "En torno al 2001 en la narrativa argentina", Sylvia Saítta regista um retorno ao bairro na literatura dos escritores argentinos mais jovens. Para a autora, o movimento de retirada para os bairros produz-se como resposta à crise social: "la literatura argentina se territorializa y vuelve al barrio, representado como el ámbito donde es posible la organización de solidaridades y cooperaciones, como base de la acción colectiva y fuente de identificación" (Saítta, 2014, p. 143).

Tomando em consideração esta constatação dum "retorno ao bairro" na literatura argentina, que a autora confirma na sua leitura de La villa, parece haver duas posições em tensão: enquanto que para esta ensaísta, as transformações do mundo do trabalho e a crise social convertem o bairro em refúgio e terreno de socialização política e inscrição coletiva, Ludmer vê nos bairros do tipo "ilha urbana" lugares de barbárie ou espaços de abandono. As diferentes zonas do bairro de Flores aparecem naturalizados, tal como Ludmer descreve com o exemplo de Angosta de Héctor Abad Faciolince, tomam-se por naturais as divisões em classes sociais e zonas da cidade. No romance de Aira, Maxi é filho dum comerciante abastado e a sua família mora num apartamento moderno perto da praça de Flores (Aira, 2001, p. 12). Ele não sabe muito bem como imaginar os "pobres" e surpreende-se quando vê que as pessoas da villa se vestem e se comportam do mesmo modo 
que outros argentinos. Maxi conclui que "lo único que los clasificaba de pobres era que habitaban esas viviendas precarias" (Aira, 2001, p. 69). Desta forma, é a cidade que faz deles "pobres". As diferentes classes sociais da cidade são naturalizadas e claramente visíveis no romance. As duas partes do bairro de Flores, a parte "burguesa" e a parte da villa, funcionam como unidades determinantes, como se todos os habitantes da villa tivessem um elemento em comum, "natural" deles, de outro modo não viveriam ali.

Em Aqui América Latina, Josefina Ludmer adapta a noção de território de Deleuze e Guattari (1994) que definem o território como distância crítica entre os corpos de, no mínimo, dois membros da mesma espécie, humanos ou animais. Parafraseando a C. Schmitt, Ludmer explica que numa visão política cada território é designado como tal pelo fato de obedecer a um poder soberano que não permite nenhum poder alternativo e faz uso de violência quando se vê ameaçado. Assim, a autora define o território como organização do espaço em relação aos sujeitos a ele vinculados:

Los cuerpos son anexos al territorio; desde esta perspectiva, un territorio es una organización del espacio por donde se desplazan cuerpos, una intersección de cuerpos en movimiento: el conjunto de movimientos de cuerpos que tienen lugar en su interior y los movimientos de desterritorialización que lo atraviesan. Y eso puede verse a través de las ficciones (Ludmer, 2010, p. 123).

Apontando para a chamada literatura autónoma, a autora nota que a imaginação territorial na América Latina remete para uma história própria, que no século XX foi constituída pelos clássicos: Jorge Luis Borges com "los orilleros", Juan 
Rulfo com Comala, Juan Carlos Onetti com Santa Maria e Gabriel García Márquez com Macondo. Ludmer pronuncia-se a favor de estudar novas formas de compreensão destes processos: "estamos en una economía que organiza el territorio de otras maneras y en una nueva forma de territorialización del poder. En otros modos de territorialización artística y en otras desterritorializaciones" (Ludmer, 2010, p. 124). A partir destes pensamentos Ludmer outorga uma dimensão política a sua abordagem.

No romance de Piglia há vários tipos de máquinas que interagem com as personagens - desde a máquina de narrar no museu, passando pelas câmaras de vigilância, até ao pássaro mecânico que poderiam ser entendidas como corpos. $\mathrm{Na}$ forma como se vinculariam aos territórios, as máquinas são claras manifestações do poder soberano, exercido sobre territórios geográficos e virtuais.

$\mathrm{Na}$ leitura de La villa de Aira, torna-se visível a ligação das figuras aos respetivos territórios que as definem como tais e também a distância crítica que existe entre os corpos que os delimitam: entre os villeros e os não villeros existe uma divisão de zonas; o limiar, lugar em que acaba uma parte do bairro e começa outra é reconhecido amplamente como tal. O protagonista Maxi é um jovem de classe média com muito tempo livre e que se dedica a treinar num ginásio. Maxi começa a ajudar os moradores da villa quando estes ao cair da noite saem a percorrer o bairro e recolhem objetos e materiais do lixo. Guiado pela curiosidade, o jovem ganha o hábito de acompanhá-los. Dão-se referências geográficas precisas: o território habitacional dos cartoneros é localizado na baixa de 
Flores e o território de recolha do lixo vai desde a parte baixa até à Avenida Rivadavia e às vias de comboio (Aira, 2001, p. 15). Os moradores de ambas as zonas de Flores têm preconceitos estabelecidos sobre os pertencentes aos outros locais baseados na ligação ao território. Há portanto, identidades territoriais ou "de bairro". No romance nenhuma personagem sai do bairro. Este facto pode remeter a um fenómeno de territorialização tal como Saítta observa. Contudo, a pertença que confere a identidade territorial a Maxi é bem diferente da forma de pertença das pessoas da villa, que por sua vez também difere do caso do polícia Cabezas. Quando Vanessa, a irmã de Maxi, vê Adelita, a jovem da villa que trabalha como empregada doméstica na casa em frente, pensa que ela se assemelha a uma barata: "negra como una cucaracha, pequeñita como una niña de diez años" (Aira, 2001, p. 48). Vanessa vê Adelita junto a um rapaz, que parece ser "O Pastor" e filho da Juíza. Esta pessoa é imediatamente associada por Vanessa com perigosos narcotraficantes. A parte do bairro que compõe a villa não está isolada, há relações estabelecidas que interferem no espaço desde fora, por exemplo, refere-se no romance o negócio imobiliário e de drogas. Em Flores recrutam-se empregadas domésticas na villa. Os vizinhos da familia de Maxi são os proprietários de casas que alugam a membros da comunidade evangélica cujo chefe é suspeito de esconder um negócio de droga. Os responsáveis dessa comunidade também são donos de uma frota de autocarros e duma loja onde funciona o ginásio que frequenta Maxi, e que mais tarde é vendida, e de quintas com centros de reabilitação de tóxico-dependentes na periferia de Buenos Aires. Pode 
supor-se que isto seja um exemplo dos múltiplos tipos de movimentos de desterritorialização que atravessam os territórios urbanos, como refere Ludmer. Ao longo da narração, o antagonismo entre as duas partes de Flores cresce e várias personagens ficam curiosas acerca do centro da villa vendo-se envolvidas no caso.

\section{A “ilha urbana” em La villa de César Aira}

No conjunto de textos narrativos em que Ludmer identifica a figura da ilha urbana, a zona da cidade onde se forma esta "ilha urbana" muitas vezes dá nome à ficção. Além de La villa de Aira, Ludmer menciona La azotea de Fernanda Trías (2001) e Salón de Belleza de Mario Bellatin (1994). A “ilha urbana” é, ao mesmo tempo, um conceito que se localiza na ordem simbólica da cidade, no regime territorial urbano latinoamericano, ela designa um território dentro da cidade que pode ser uma área, um edifício, uma habitação ou algum outro espaço (Ludmer, 2010, pp. 130-131). A ilha urbana é um regime territorial de significação reconhecível pelos seguintes critérios: é um espaço relativamente aberto mas separado do resto da cidade; tem regras próprias; é formado por fragmentos e ruínas e, é visto como natural ou constituído como elemento natural num espaço urbano. Para a autora, a ilha urbana é "una maquina naturalizadora de lo social, que opera por irrupciones de 'la naturaleza humana' o, simplemente, de 'la naturaleza"' (Ludmer, 2010, p. 132). O regime da ilha inclui corpos, animais 
e humanos, de qualquer classe social. No seu interior já não se opõem o urbano e o rural, o humano e o animal.

O conceito da "ilha urbana" tem muitas semelhanças com o que Michel Foucault propõe chamar "heterotopia", tanto que é difícil distinguir a especificidade da figura de Ludmer. Em 1967, Foucault sugeriu um novo conceito espacial ou espaçotemporal, que seria a "heterotopia" e como variante da mesma "heterocronia" (Foucault, 1984). Foucault introduz a sua proposta assinalando que a grande obsessão do século XIX foi a história com os seus temas como desenvolvimento, crises, ciclos e dum passado sempre acumulativo. Por seu turno, a época do presente [1967] debate-se à volta do espaço; sendo esta a época da simultaneidade, do lado-ao-lado, do disperso. Foucault sugere descrever estes espaços diferentes olhando para a combinação de relações que os definem. Há, por exemplo, espaços móveis, como no comboio, ou espaços de relaxamento temporário, o cinema ou a praia. Os principais tipos de heterotopia são para o autor francês os espaços que se relacionam com todos os outros espaços e que os contradizem. Pode assumir formas muito diferentes: é capaz de justapor um espaço ou vários espaços. Tal como as ilhas urbanas, as heterotopias supõem sempre um sistema de abertura e fechamento e são espaços de exclusão:

There are others, on the contrary, that seem to be pure and simple openings, but that generally hide curious exclusions. Everyone can enter into thew [sic] heterotopic sites, but in fact that is only an illusion- we think we enter where we are, by the very fact that we enter, excluded. (Foucault, 1984) 
As heterotopias também têm uma função. Esta desdobra-se entre dois polos; ou tem como objetivo criar ilusão dum espaço real (por exemplo, um bordel), ou, ao invés, o de criar outro espaço mais perfeito (compensação), cujo exemplo seriam as colónias jesuítas.

Neste ponto pergunto-me se as "ilhas urbanas" de Ludmer não teriam uma função semelhante, ou seja a função da ilusão dum espaço real, que, ao mesmo tempo, contradiz o resto da cidade. A ilha urbana também reúne muitos outros espaços em si, e os romances que têm ilhas urbanas como localização do seu argumento confirmam que estas, como a villa no romance de Aira e, também, o Asilo no romance de Levrero e, talvez, o Museu de La ciudad ausente são grandes reservas de imaginação.

Josefina Ludmer explica que a ilha é como se fosse um espaço de acesso público que tem limites precisos e está, geralmente, fechado, mas no qual em princípio é possível entrar, e que por dentro é regido por regras específicas. Tanto as personagens como a ilha urbana em si recebem dessa forma a sua posição afueradentro: "los límites o cesuras identifican a la isla como zona exterior/interior: como territorio adentro de la ciudad (y por ende de la sociedad) y a la vez afuera, en la división misma". É um lugar onde as pessoas podem isolar-se, e, de certa maneira construir a sua comunidade. "Los habitantes de la isla (...) parecen haber perdido la sociedad o algo que la representa en la forma de familia, clase, trabajo, razón y ley, y a veces de nación” (Ludmer, 2010, p. 131).

A nível narrativo, a ilha urbana caracteriza-se por uma subjetividade ou personagem central que entra no espaço que 
compõe a ilha urbana através de vínculos sociais e ao mesmo tempo está visto desde fora por um narrador em terceira pessoa que entra e sai. Ludmer explica que o território da ficção se constitui assim: "Cruza, entra y queda allí por un tiempo, el que dura la ficción" (Ludmer, 2010, p. 132). A ilha pode ser um território físico mas também pode ser um espaço não-físico, um “eu” ou uma instituição, como em Derretimiento de Daniel Mella. Todos estes critérios estabelecidos por Ludmer comprovam-se em La villa de César Aira: "Esta ciudad de la pobreza dentro de la ciudad podía obedecer a sus propias leyes" (Aira, 2001, p. 33). O protagonista, Maxi, consegue passar as limitações e ver a villa por dentro e desde fora, mas a sua entrada constitui um acontecimento pouco comum. O narrador em terceira pessoa entra e sai com ele. Sendo exterior e interior ao mesmo tempo, a ilha urbana localiza-se, portanto, dentro da cidade e da sociedade, e, ao mesmo tempo, fora delas.

Além de referir uma configuração social ou humana, desde o ponto de vista formal a "ilha urbana" é uma construção precisa, pensa-se como um fuera ou um "más allá verbal y narrativo" (Ludmer, 2010, p. 134). A irmã de Maxi confunde as pessoas da villa, não são "legíveis" para ela: "En esas razas, además de no reconocer a los individuos, no podía calcularles la edad" (Aira, 2001, p. 49). Em La villa, os habitantes da ilha estão num afueradentro verbal, já que falam castelhano, mas com sotaque peruano ou boliviano, que a Maxi soa estranho.

Talvez pela sua posição de afueradentro, ou também através dos procedimentos de distanciamento, estranhamento e ambiguidade, a descrição da villa pode ser relacionada com o 
género fantástico: "ya fuera ilusión, ya confusión, le parecía ver, rumbo al centro inaccesible, torres, cúpulas, castillos fantasmagóricos, murallas, pirámides, arboledas" (Aira, 2001, p. 36). Reconhece-se a índole duma ilha urbana em La villa pelo espaço da ação narrativa, isto é o bairro de Flores dividido entre a parte caracterizada pelo padrão quadriculado, próprio do modelo de urbanização da cidade letrada traçado por Ángel Rama, e a parte da aglomeração de construções ilegais que compõem a villa miseria. Esta última é alcunhada "la calesita" o carrossel - por ser redonda e fortemente iluminada, com ruas que não obedecem aos ângulos retos. O espaço limiar entre a cidade e a villa é visível no romance: "[...] el foco de violencia que se había generado a la puerta de esa villa circular, a la que en la jerga de la policía llamaban "la calesita" (Aira, 2001, p. 40). De noite, nos seus carros, os traficantes dão voltas em redor dela, e o polícia vai atrás deles. "Todos sabían que ahí se vendían drogas en gran cantidad, pero nadie sabía cómo entraban y cómo salían" (Aira, 2001, p. 42). Todas as villas aparecem em sítios limitados, mas a sua população aumenta sem cessar, devido ao seu "crecimiento vegetativo descontrolado" e também pelas migrações desde o interior do país e desde os países limítrofes para a cidade (Aira, 2001, pp. 33-34). Também outras diferenças estruturais que saltam à vista, por exemplo a iluminação parece crescer como se fosse algo vegetal.

Saítta observa que perante a desarticulação da estrutura social vários romances argentinos apresentaram espaços ligados ao mundo familiar, da infância e ao privado, que procuraram reconstruir no plano do simbólico os âmbitos de 
pertença e redes de solidariedade. A autora alega que em La villa de César Aira, o bairro e a villa miseria são cenários dum mundo integrado:

[...] reaparece la villa miseria como el escenario de un mundo solidario, con reglas claras de convivencia y de solidaridad; un universo integrado, que, al igual que en los textos de Verbitsky y Conti, tiene como estructura básica a la familia, con la diferencia de que se trata de una familia "en movimiento": es toda la familia (madre, padre e hijos) la que sale a revolver basura para buscar allí todo lo que pueda servirles. (Saítta, 2006, pp. 99-100)

Contrastando com a leitura de Saítta, as ilhas urbanas definidas por Ludmer formam-se como espaços temporários para pessoas de diferentes classes sociais que perderam os seus vínculos de pertença em forma de família, classe, trabalho, razão e lei e mesmo de nação. A criação da comunidade ocorre estimulada por necessidade e falta de alternativa. A ilha é composta no mínimo por duas diferentes classes sociais e constitui portanto uma forma transversal à sociedade. Os habitantes definem-se em plural e formam como uma comunidade, pode ser "un grupo de enfermos, de locos, de monstruos o animales" (Ludmer, 2014). Quanto à estrutura da ilha, Ludmer define que ela tem um nível baixo, um "subsolo" que reduz as pessoas a matéria orgânica ou animal, e outro nível que eleva as pessoas e matérias a um estatuto alto ou espiritual. Pode observar-se em La villa de Aira e também nas três partes da Trilogía involuntaria de Levrero que em grande parte das situações as personagens interagem para satisfazer necessidades básicas, a comida, o sono, o sexo, o medo, ou seja, partes que podem ser associadas ao nível baixo da ilha 
urbana que Ludmer descreve. O território da ilha urbana abandona-se ou desintegra-se quando termina a ficção:

Desde una posición afuera-adentro (de la ciudad, de la clase social, de la familia o de la nación), la narración delimita la topología exacta del territorio y su régimen de significación, y pone en escena los sujetos de la isla urbana. Y después gira sobre sí misma, indefinidamente o hasta "el fin", para tratar de borrar el territorio y el sentido. La isla se construye para ser destruida y el fin del territorio es el fin, también, del sentido: al fin, los habitantes la abandonan. Un sentido territorial y provisorio. (Ludmer, 2010, p. 135)

No romance de Aira, logo que Maxi entra na villa, começa a auto-destruição da ilha urbana. Em quase todo o tempo da história, Maxi aproxima-se e leva com ele outras pessoas, perto da entrada e à volta da ilha urbana, frequentam a zona limite. A tensão narrativa aumenta com a iminência duma tempestade na parte final do romance, e, quando finalmente começa a chuva torrencial, todas as personagens penetram no território da villa. No interior revela-se que esta não tem centro. Para as personagens, o bem e o mal é cada vez mais difícil de distinguir, neste espaço que parece fantástico ou onírico, até se fundirem no momento em que entram em jogo os meios de comunicação que espalham informação duvidosa, e porque vários personagens estão sob o efeito da droga "proxidina". Enquanto tudo isto acontece, Maxi está a dormir numa das pequenas casas da villa e as outras personagens perguntam-se: “¿Pero entonces, la villa podía 'girar”? ¿Era posible? Quizás no había estado haciendo otra cosa desde épocas inmemoriales. Quizás toda su existencia se había consumado en una rotación sin fin" (Aira, 2001, p. 168). 
Podem discutir-se diferentes possibilidades de compreender, identificar e interpretar o conceito de "ilha urbana". Não fica claro se Saítta na sua leitura se refere geralmente à representação de bairros na literatura recente ou se fala especificamente das ilhas urbanas.

Em muitos casos é com nostalgia, ou ironia, nota Saítta, que os romances contemporâneos em questão expõem hipóteses sobre a sociedade a partir da criação de espaços alternativos à dissolução do quadro social dos começos do século XXI. A autora refere os mesmos exemplos que Ludmer. Parece até responder-lhe diretamente, relativizando a tonalidade de rutura e dissolução das grandes tradições da literatura argentina que Ludmer aplica em Aqui América Latina:

Aun cuando los tiempos de la globalización, la postautonomía y las presiones del mercado editorial parecieran imponerse, la literatura argentina continúa pensándose en el diálogo, la confrontación o la tensión, con una tonalidad, una entonación, la fidelidad a ciertos espacios, que son constitutivos de lo que hoy se reconoce como literatura argentina. (Saítta, 2014, pp. 143-144)

Lido com Ludmer, o bairro em La villa me parece diferente do que descreve Saítta, mas talvez se possa considerar, que já havia na "ilha urbana", antes da entrada de Maxi, uma comunidade improvisada, tal como a vêem Saítta e Paola Cortés-Rocca. Para a última, é em jeito burlesco ou com a distância da ironia que os bairros pobres estão a ser colocados no centro dos romances; mas destaca que as villas são identificadas como espaço emblemático da globalização capitalista, "que más que ser una excepción constituye el corazón mismo de la metrópoli latinoamericana", e que nos 
romances funcionam como lugar a partir do qual se deve pensar a política atual: "Lejos de coleccionar estampas exóticamente embellecidas de la pobreza o de presentarlo como el lugar de la resistencia épica o la injusticia sufriente, lo conceptualizan como el lugar desde el cual pensar nuevas aproximaciones a la política contemporánea" (Cortés-Rocca, 2014, p. 3). Na questão da representatividade aparece esta contradição: "En estas novelas también la villa es, pese a sus límites y alambrados, una miniatura de la nación e incluso de la región. Las villas que proponen las novelas ${ }^{4}$ son [...] zonas donde efectivamente hay un esfuerzo -tal vez irónico- por construir lo latinoamericano, como una serie de rasgos en común sino como una suerte de deposición o exclusión compartida." (Cortés-Rocca, 2014, p. 3).

As "ilhas urbanas", os espaços de cidade-campo, e os conceitos de "realidadficción", "afueradentro" surgem a partir de processos de sobreposição e fusão e deixam de ser representativos. Ao mesmo tempo, a indefinição em relação às posições políticas ou ideológicas, o apolítico, a fragmentação, o individualismo e o deslocamento para outras práticas sociais parecem ser representativos para a época atual. Este tipo de representação nacional, característico da literatura moderna, e nos termos de Ludmer, autónoma, acabou. Enquanto, por exemplo, Macondo representa a Colômbia e também a América Latina, as personagens das ilhas urbanas não reconhecem

\footnotetext{
${ }^{4}$ La villa de César Aira (2001), La boliviana de Ricardo Strafacce (2008) e La virgem Cabeza de Gabriela Cabezón Cámara (2009).
} 
espaços representativos no sentido político. Ludmer diz isto expressamente:

La isla urbana no es un microcosmos ni una metonimia ni reproduce la sociedad [...] Es un instrumento conceptual; una secuencia sobre la irrupción de la naturaleza en la sociedad y al mismo tiempo un régimen de sentido. Satura la imaginación pública del presente (que preferimos imaginar como anónima y colectiva: a la vez un instrumento para hacer presente y un instrumento crítico) y permite pensar (o ver: el presente es el tiempo de la imagen y de la inmanencia) lo social sin la sociedad, lo histórico sin la historia y lo político sin la política. (Ludmer, 2010, p. 137)

Se há algo representativo para as sociedades latinoamericanas da época atual na literatura é que existam ilhas urbanas.

José Ramón Ruisánchez Serra relaciona a construção heterotópica na literatura argentina com o período pósditatorial; em concreto com o segundo momento dentro da pós-ditadura, a fase em que surgiram as perguntas sobre se o luto se devia prolongar indefinidamente, ou se se devia pensar num fim do luto, e, de como redefinir a cidadania e a nova ética da representação e da nacionalidade. E explica a coexistência dos tempos e dos espaços: "Estas preguntas deben, desde luego, examinarse a la luz de los posteriores desastres del mercado y el sistema democrático, desde la ventaja posicional que nos ofrece nuestro presente" (Ruisánchez Serra, 2006, p. 44). Através da proposta de ler nos dois romances heterotopias, o autor estabelece a ligação entre La ciudad ausente e La villa, e ainda sugere que se pode ler o 
título de La villa como uma parodia da seriedade dramática de La ciudad ausente de Piglia:

A semejanza de La ciudad ausente, parece tratarse de una novela de penetración progresiva en el espacio misterioso donde se ubica un (el) núcleo narrativo de la contrahistoria, o la Historia. En este caso, en lugar de la máquina en el museo, se trata del centro oscuro, desconocido, de una villa incorporada al tejido urbano tradicional en forma de inevitable suplemento (cuya peligrosidad es parte de la actividad narrativa a la que invita). (Ruisánchez Serra, 2006, p. 54)

A aproximação dos romances dos dois escritores tão frequentemente contrapostos é, contudo, relativizada pelo autor.

A semelhança entre "ilhas urbanas" e "heterotopias" pode ser produtiva para análises do tipo que propõe Ruisánchez Serra. No entanto, haveria que estudar melhor a noção de "ilha urbana" de Ludmer para não incorrer em generalizações.

\section{Possíveis ilhas urbanas nos romances de Ricardo Piglia e Mario Levrero}

Para um melhor entendimento das figuras conceptuais sugeridas por Josefina Ludmer, como indicador do novo regime pós-autónomo de sentido das narrativas latino-americanas, pode ser verificada a sua aplicação também nos romances de Piglia e Levrero. Propôs-se a hipótese de que La ciudad ausente, de Piglia, aproximar-se-ia à categoria de "literatura autónoma", uma vez que o seu autor é referido como escritor-intelectual e 
as suas obras são pensadas como centrais no cânone literário argentino e porque os romances abordam questões nacionais. Saítta assinala que Respiración artificial, de 1980, é "considerada por muchos críticos como la novela más representativa de la literatura argentina escrita durante la dictadura" e "convirtió a Piglia en una suerte de referente generacional, rápidamente consagrado por la crítica y sus pares literarios" (Saítta, 2014, p. 134). Para París de Mario Levrero, não havia indícios que permitissem uma classificação preliminar.

Pergunto-me, aplicando um modo de leitura experimental, se se pode encontrar a figura da "ilha urbana" no romance de Piglia. Em La ciudad ausente, a natureza e os relatos do campo estão representados no Museu, expõe-se também o relato de Macedonio em que se imagina uma cidade-campo futura (Piglia, [1992] 2013, p. 55). Ainda assim, ao invés da sugestão de Ludmer duma incorporação do campo na cidade, estabelece-se uma grande distância cultural e política entre a vida na cidade e a vida no campo. O romance também inclui representações de espaços rurais descritos como lugares oprimidos e distópicos, tanto quanto os citadinos. Estes espaços, em La ciudad ausente, existem claramente separados da cidade, não foram absorvidas por ela. O campo aparece em forma de fantasias, memórias, esperanças, e notícias que as personagens trazem do campo, mas é também visitado nas viagens do protagonista que investiga a origem da máquina. $\mathrm{Na}$ maioria das vezes que se menciona o campo evoca-se uma imagem negativa, quase apocalíptica, por exemplo, quando Lucía diz a Junior: "Son todos drogadictos, en el campo. Alucinados" e "En el campo no duermo. Para donde uno mira 
hay droga y basura" (Piglia, 2013 [1992], p. 22). Na quarta parte, Júnior finalmente chega à ilha Santa Marta no Paraná, referida por Elena, onde, a máquina estaria, talvez, a salvo da influência do estado.

Em La ciudad ausente os espaços têm limitações, estão fechados mas não são impenetráveis. O museu, os hotéis e o subte $e^{5}$ são, em princípio, lugares públicos e reúnem pessoas que perderam o direito de incorporar as suas histórias na memória cultural. Também há personagens que perderam a família, ou a confiança na lei. Porém, nem todas as instituições penitenciárias ou psiquiátricas ou hotéis podem ser ilhas urbanas - é normal que este tipo de lugares albergue pessoas em posição exterior-interior da cidade (da sociedade, da nação, do trabalho, etc.). Pode então o hotel onde Junior é convocado pelas chamadas telefónicas ser compreendido como ilha urbana? Como se interpretaria o espaço da galeria subterrânea por baixo da Avenida Nueve de Julio, junto à estação de metro, que é o lugar onde se estabeleceu o centro de informação e resistência clandestina e onde alguém pendurou uma fotografia de Macedonio Fernández na parede? Pode pensar-se na fotografia como o altar que funciona como nível espiritual na "ilha urbana"? Talvez os espaços mencionados sejam heterotópicos, mas não ilhas urbanas, se entendemos que uma ilha urbana, como a pensou Ludmer, dá nome à narração e se sustem como espaço central do argumento do romance. Seguindo este raciocínio, apenas o museu em que se expõe a máquina de narrar será uma ilha urbana, pois é central

${ }^{5}$ Metro. 
na narração e é enclausurado pelo governo ou abandonado pelos protagonistas no final do livro.

Segundo Ludmer, "la isla -un tipo específico de régimen de significación, un instrumento conceptual en imagen para ver los años 2000- es una forma transversal a la sociedad porque mezcla por lo menos dos clases [...], la mezcla social es el centro de la narración y el "procedimiento universal"' (Ludmer, 2010, p. 132). Pode-se reparar que no romance de Piglia, o sítio em que se misturam vozes de gaúchos e de operários, a literatura de Borges, de Ricardo Güiraldes e de Roberto Arlt, é o texto da máquina.

A "ilha urbana" encontrar-se-ia então no território da língua escrita como também a "exposição universal" pode ser encontrada na forma dos relatos que circulam na cidade. Alfonso Macedo Rodríguez propõe analisar o romance de Piglia dentro do contexto de literatura fantástica rioplatense e examinar, nessa relação, a função da metaficção e intertextualidade; ou seja, ler La ciudad ausente como narração reflexiva sobre o narrar.

A máquina de Macedonio, que tece redes de texto até unir toda a produção literária, é uma metáfora para a literatura. Ludmer sugere o conceito como modelo de síntese temporal e espacial com a qual se poderia perceber a literatura atual. $\mathrm{O}$ museu como lugar central do romance de Piglia já é um elemento que sugere uma exposição, isto é, um conjunto de elementos tomados a partir de diferentes espaços e tempos, demostrando diversidade e acumulando o tempo. Acredito que seria uma tentativa válida ler La ciudad ausente com a figura de 
"exposição universal" e procurar definir melhor a figura teórica de Ludmer, para distingui-la de figuras semelhantes, usuais na literatura autónoma. Além disso, seria um tema a investigar dentro das temporalidades mais do que dentro das territorialidades que neste lugar desvia do enfoque do trabalho.

Também no romance de Levrero se encontra este tipo de lugar ambíguo "fechado-aberto", “exterior-interior" ou "afueradentro" que alude à ilha urbana, mas que me parece que não é: o lugar central onde se desenvolve o argumento de París é um asilo que se assemelha a uma prisão, a um lar de caridade, a um bordel ou manicómio. Em La ciudad e El lugar, os espaços revelam-se mais amplos no seu interior do que parecem por fora, os prédios crescem por dentro, abrindo-se para habitações e corredores infinitos. Em París, o protagonista é levado para o Asilo imediatamente após a sua chegada, porque não dispõe de dinheiro para pagar o táxi. $\mathrm{Na}$ receção da instituição cuja função é ambígua, um homem vestido de padre distribui os quartos e entrega ao protagonista um catálogo com imagens de mulheres nuas, do qual ele um pouco envergonhado acaba por escolher uma. Os espaços e as personagens são contraditórios, traçados com cinismo ou ironia. Há vezes, por exemplo, que o protagonista consegue sair pela porta do Asilo e voltar a entrar sem problemas, e outras vezes em que não. Parece mais fácil entrar do que sair, como nas heterotopias que descreve Foucault. A comunidade do Asilo assemelha-se àquela descrita por Ludmer como "un grupo genérico de enfermos, locos, prostitutas, okupas, villeros, inmigrantes, rubios, mano de obra, monstruos o freaks" (Ludmer, 2010, p. 131). No entanto, não encontramos 
diferentes classes sociais. O narrador em primeira pessoa, que dá mostras de ser o mesmo em toda a Trilogía involuntaria, por vezes parece ter perdido a razão, também carece de trabalho e família. O Senhor Juan Abal, que afirma estar preso neste lugar desde há três anos, ocupa o mesmo quarto e busca a proteção do protagonista. Diz-lhe que o lugar é, na realidade, um mosteiro e todos eles são monges presos (Levrero, 2016 [1980]). Refere-se que o homem "trabalhava" na garrafa, mas não fica claro em que consistia a sua atividade. Ele conta que tem passado anos escondido numa garrafa de cartão prensada, uma propaganda de Seven-Up, junto ao rio Sena. Foi encontrado e levado para o Asilo. Abal explica que Angelina vivia com eles debaixo das pontes. O protagonista, furioso, manda-o embora. O velho adverte: "Es inútil. ¿Cree que no se me ha ocurrido hacerlo en todos estos años? Pero dependo de ellos, ellos me alimentan y me cuidan, no podría sobrevivir sin ellos" (Levrero, 2016 [1980], p. 344). Mais adiante, o protagonista apercebe-se de que as mulheres que pareciam prostitutas formam parte da Resistência e estão disfarçadas dessa maneira para ter acesso livre aos quartos. Na cidade ameaçada pelas tropas de Hitler, estas mulheres atraem o protagonista, que afirma não estar interessado em política, mas não o deixam aproximar-se. $\mathrm{O}$ protagonista é estrangeiro e irrompe neste círculo de Resistência, também por isso, de certa maneira, o asilo de Levrero poderia ser uma ilha urbana. Ludmer explica: "De hecho, el territorio se constituye en las ficciones cuando se rompe la homogeneidad social y se produce esa contaminación. Se constituye desde afuera, cuando la subjetividad central [...] impulsada por una necesidad 
o fuerza ciega (accidente-enfermedad-peste-hambre-sueñosexo), cruza la frontera que es el límite de la isla [...]" (Ludmer, 2010, p. 132).

O Asilo não tem regras claras que o diferencie do resto da cidade, em vez disso salienta a ausência de regras lógicas e físicas sociais em todos os ambientes do romance. Também o espaço social em París, tanto no privado como no público, mostra-se com características inconstantes e frágeis.

A outra possibilidade de ler París seria pensar numa ilha (urbana) interior ou psicológica. O romance de Levrero desenvolve-se em torno duma procura do espaço pessoal ou do território do "eu" que se identifica com a cidade. Em París, a construção narrativa é feita em primeira pessoa e não a partir de um narrador em terceira pessoa que vê o protagonista entrar na ilha urbana, como descreve Ludmer. Contudo, a autora não deixa explicações sobre como se caracterizaria um "eu" como "ilha urbana". E não se pode perder de vista que na trilogia de Levrero este espaço não é constituído de forma temporária, não é limitado, é constante. Em París, a forte identificação de "o eu" com a cidade claramente apresenta um problema:

La tarde era gris como la estación, como la ciudad, como yo mismo. Me siento gris por dentro y por fuera y siento vehementemente un cambio, pero desde hace tiempo me obsesiona la idea de estar demasiado ligado al mundo exterior, de que, en realidad, todo mi ser forma parte, no puedo precisar los límites: hasta ahí, el mundo exterior, aquí empiezo yo, de que no puedo cambiar mientras todo permanece inmutable alrededor, o cambia lentamente y en una dirección desgraciada. (Levrero, 2016 [1980], p. 315) 
O espaço do Asilo constituído não se abandona nem se destrói ao final da narração como seria típico para uma ilha urbana. Pelo contrário, a personagem parece estar condenada a ficar aí, eternamente. $\mathrm{Na}$ última página tenta voar, como já aprendeu anteriormente, com os anjos da Resistência, mas desta vez não consegue e cai de joelhos. O livro acaba com esta derrota.

O final de París também pode ser interpretado como uma dissolução da constelação social do espaço constituído - como ocorre segundo Ludmer com as ilhas urbanas no final dos romances - já que o protagonista fica sozinho. Ou pode ser interpretado como uma desintegração do eu no céu ou no espaço da cidade, patente em estas passagens: "Pero no necesito puntos de referencia -me dije, tratando de fortalecerme -. Necesito volar. Irme de aquí. Volar" e:

Sabía, sin embargo, que no podía hacerlo aún; sutiles lazos invisibles me mantenían atado a la ciudad, y quizá me llevara todavía cierto tiempo, aunque más no fuese algunos minutos, romperlos; el problema consistía en que no conocía la naturaleza de esos lazos. (Levrero, 2016 [1980], p. 440)

O sujeito principal é um eu que no final gira sobre si mesmo e, visto dessa maneira, é semelhante ao modo como outras ilhas urbanas giram e se desintegram, nomeadamente a villa.

Em síntese, pode dizer-se que, decerto, há nas cidades dos romances de Piglia e Levrero espaços fragmentados, ruínas, e espaços heterotópicos, mas não se configuram "ilhas" do mesmo tipo que em La villa, ou desde logo, não há informação 
suficiente para poder identificar claramente as configurações espaciais dos romances de Piglia e Levrero.

\section{A modo de conclusão}

No decorrer da "aplicação" das ferramentas de leitura sugeridas por Ludmer, ou seja, na tentativa de ler outros textos fora do corpus narrativo de Aqui América Latina, apareceram dúvidas sobre como diferenciar o que seria característico da literatura autónoma, e o que pertenceria à pós-autonomia. Contudo, na efetuada análise, encontramos que, cada um dos três romances contém tanto elementos próprios da literatura autónoma (segundo a entende Ludmer), como da pósautónoma, e podem ser lidos a partir de qualquer uma das duas formas.

Rafael Arce pergunta se a publicação de um romance "anacrónico", que pretende dialogar com Balzac, no terceiro milénio, seria, então uma provocação (Arce, 2010, p. 17). Esta pergunta é válida para todos os textos, que pertenceriam ao lado daquelas literaturas autónomas, que conviveriam com as pós-autónomas. Para Arce, esta divisão que Ludmer sugere, não é compreensível como uma convivência pacífica de modos de escrita, mas sim como uma coexistência conflituosa de modos de ler. Quando tudo depende de como se lê, como interpreta Arce e como Ludmer mesma chega a afirmar (Ludmer, 2010, p. 155), e o conflito está na leitura, e não na escrita, estamos perante um problema epistemológico. 
No que diz respeito à análise, tem de se perguntar, consequentemente, se a leitura realizada abriu conflitos ou não. Assumindo que é possível entender a autonomia e pósautonomia não como sucessão temporal mas como possíveis estados paralelos, faz sentido termos encontrado esta ambivalência nos romances de Piglia e de Levrero, pertencentes, segundo Ludmer, ao último avatar da autonomia, e, portanto legíveis consoante a perspetiva escolhida pela leitura. Mas, daí surge a pergunta de qual seria a consequência dessas leituras autónomas ou pós-autónomas.

\section{Referências Bibliográficas}

Aira, C. (2001). La villa, Buenos Aires: Emecé.

Arce, R. (2010). "La genealogía del monstruo". Alberto Giordiano (Ed.). Los límites de la literatura. Cuadernos del seminario. Centro de Estudios de Literatura Argentina Rosario: Universidad Nacional de Rosario, 17-32.

Cortés-Rocca, P. (2014). "La villa: política contemporánea y estética”. Revista de Estudios Hispánicos, 48 (1), 183-99.

Contreras, S. (2010). "En torno de las lecturas del presente". Alberto Giordano (Ed.). Los límites de la literatura. Cuadernos del seminario. Centro de Estudios de Literatura Argentina. Rosario: Universidad Nacional de Rosario, 135153 .

Dalmaroni, M. (2010). "La literatura y sus restos (teoría, crítica, filosofía). A propósito de un libro de Ludmer (y de otros tres)". 
http://www.bazaramericano.com/columnas.php?cod=19\&pd $\mathrm{f}=\mathrm{si}$

Deleuze, G.; Guattari, F. (1994). Mil mesetas. Capitalismo y esquizofrenia. Valencia: Editorial Pre-textos. (Trad. J. Vázquez Pérez e U. Larraceleta).

Foucault, M. (1984 [1967]). "Of Other Spaces, Heterotopias". Architecture, Mouvement, Continuité 5, 46-49. https://foucault.info/doc/documents/heterotopia/foucaulthe terotopia-en-html

Heffes, G. (2012). "Muerte y transfiguración de la ciudad: territorios urbanos y marginalidad". Cuadernos De $\begin{array}{llll}\text { Literatura, } & 16 & \text { (32), } & \text { 125-152. }\end{array}$ https://revistas.javeriana.edu.co/index.php/cualit/article/vie $\mathrm{w} / 4065$

García Canclini, N. (2010). Imaginarios urbanos. Buenos Aires: Eudeba.

Giordano, A. (Ed.). (2010). Los límites de la literatura. Cuadernos del seminario. Centro de Estudios de Literatura Argentina. Rosario: Universidad Nacional de Rosario.

Levrero, M. (2016 [1970/1980/1982]). Trilogía involuntaria. La ciudad. El lugar. París. Barcelona: Editorial Debolsillo.

Ludmer, J. (2010). Aquí América Latina. Buenos Aires: Eterna Cadencia.

---. (2014 [2007]). "Perspectiva humanística: escritura y ciudades en América Latina". Cátedra Alfonso Reyes. Biblioteca Virtual Miguel de Cervantes http://www.cervantesvirtual.com/obra/perspectivahumanistica-escritura-y-ciudades-enamerica-latina/.

Macedo R., A. (2010). "La metaficción y la intertextualidad: figuras de lo fantástico en La ciudad ausente”. Signos Literarios, 10, 57-75. 
Piglia, R. (2013 [1992]). La ciudad ausente. Barcelona: Editorial Debolsillo.

Rama, Á. (1998 [1984]). La ciudad letrada. Montevideo: Arca.

Rivadeneira, B. G. (2014). "La Ciudad como imposible y farsa. Una lectura crítica de Mario Levrero". El taco en la brea, 1 (6), 108-121.

Ruisánchez Serra, J. R. (2006). "Heterotopías: imaginación política y espacio en Piglia y Aira”. Signos Literários, 2 (3), 43-60.

Saítta, S. (2006). "La narración de la pobreza en la literatura argentina del siglo veinte”. Revista Nuestra América, 2, 89102.

---. (2014). "En torno al 2001 en la narrativa argentina". Literatura y lingüística, $29, \quad 110-131$. https://dx.doi.org/10.4067/So716-58112014000100008

Topuzian, M. (2013). "El fin de la Literatura. Un ejercicio de Teoría Literaria Comparada". Castilla. Estudios de Literatura, 4 , 298-349.

Fecha de recepción: 12/08/2019

Fecha de aprobación: 10/03/2020 